\title{
Educational Deprivation among Women in Rural Areas: A Study on Valappurnadu Village in Kolli Hills Block of Namakkal District in Tamil Nadu
}

\author{
A. Saravanan* \\ Assistant Professor of Economics, J.K.K.Nataraja College of Arts \& Science, Komarapalayam, Tamil Nadu, India; \\ saravananchamp@gmail.com
}

\begin{abstract}
The study explores the socio-economic characteristics and educational deprivation prevailing among tribal women in Kolli Hills Block of Namakkal District in Tamil Nadu. A multistage random sampling technique was used to collect the data from 144 respondents from Valappurnadu village in Kolli Hills block of Namakkal district. The selected respondents were interviewed personally using pre-tested well structured interview schedule. The data were analyzed using appropriate statistical tools. The results of the study showed that there is a need for education of parents, particularly mother in reducing school dropout rate for girls. Female work participation plays a strong role in promoting secondary schooling in these areas.
\end{abstract}

Keywords: Deprivation, Dropout, Education, Tribal Women

\section{Introduction}

Women have been deprived of their right to equality in almost every field. In other words, in a male-dominated society, the subordination of women and discrimination on the basis of gender has prevailed through the millennia, irrespective of country, culture, society and civilization. While causes and consequences for the discrimination are many and vary from country to country, discrimination against women is widespread and deep rooted in our social system. Even in highly industrialized countries, such as the United States of America, France and Switzerland, women made an impact only after a long struggle. In USA it took 80 years (from 1840 to 1920) for women to obtain the right to vote. France conferred the right to vote on its women citizens in 1944, whereas in Switzerland women were granted their right to vote in 1971, much later than in India (1950). Though gender discrimination is witnessed in every sphere of a male dominated society, discrimination against women is widespread in the area of education. Therefore, the education of women calls for urgent appeal and meticulous attention in order to reduce the inequalities, exploitation and discrimination against the marginalized groups of society and thus eliminate the thousands of social evils.

The problem of women illiteracy has also been exacerbated due to low enrolment and high dropout rates among girls who enter the formal system of education. While the enrolment of girls in the schools has shown a steady increase, it is still not commensurate with the enrolment rate of boys. The dropout rate among girls, particularly those who live in rural areas, continues to be very high. In the light of these facts, major reasons for education deprivation among women are early marriage and dowry, reluctance to send girls out of the house after puberty, high intensity of poverty and parent's inability

*Author for correspondence 
to bear educational expenses, lack of access to schools, shortage of women teachers, lack of infrastructure facilities, need for girls to help in the farms or family occupation or household chores or responsibility of looking after younger siblings. Hence, the present study on "Educational Deprivation among Women in Rural Areas: A Study on Valappurnadu Village in Kolli Hills Block of Namakkal District in Tamil Nadu" is an attempt on this direction.

\section{Objectives}

- To identify the socio-economic characteristics of tribal households

- To analyse the educational deprivation among tribal women

- To suggest measures suitable to the overall empowerment of women in Kolli Hills Block of Namakkal District in Tamil Nadu.

\section{Review of Literature}

Cladwell et al. [1] in a study found that girl's absenteeism from school sharply gliding up once they reach a certain age; 34 percent of girls are in schools at the age of 12 but their retention falls to 11 percent by the time they are 15 years. Nearly one-fifth of the girls are not in school after puberty. They have also emphasized that this aspect is largely apparent among the peasants, artisans and Muslims but has little significance among the educationally advanced Brahmins, Jains and Lingayats. Sujatha [2] in a study in Andhra Pradesh recorded high absenteeism in grades 1 and 4, rather than in grades 2 and 3. She observed that very young children and those old enough to help in household work were irregular in school attendance for such reasons.

Unni [3] in a study in Gujarat, found that the school enrolment of girls was increasing to a maximum until the age of 10-11 years after which it was declining. The most probable reason for this is puberty after which parents withdraw them from school. A study by Dreze and Gazdar [4] based on a survey in UP supports this contention. The distant location of schools was also understood to be the prime reason behind female dropout rates. Nambisan [5], Majumdar [6] and Srivastava [7] have also referred to children's lack of interest in education to be the prime reason for dropping out.

Shivalli R. et al [8] reported that mostly non- school going girls hailed from the family of low family income in their study made in rural Northern Karnataka. Khan S. et al [9] found that the educational status of the dropouts' parents was very low as majority of mothers $(65 \%)$ and fathers $(60 \%)$ were illiterates and mostly girls belonged to medium income group in their study in Danipur block of Aligarh district.

\section{Profile of the Study Area}

Kollimalai taluk falls in the southern part of the Eastern Ghats of Namakkal district, which is a mountain range that runs mostly parallel to the east coast of peninsular India. It is surrounded by Salem and Tirchirapalli districts in the East, Erumaipatti block in the South, Sendarmangalam block in the West and Namagiripet block in the North. The geographical area of the taluk is $371.3 \mathrm{sq} . \mathrm{km}$, out of which more than 65 percent of the areas were covered under forest, accounting for 11.02 percent of the area of Namakkal district. The total rural population of the Kolli Hills block according to 2011 census was 40,479 . The sex ratio of the block population was 974 female out of 1000 males. The population of Scheduled Caste and Scheduled Tribes of the block was 668 and 38,678 respectively. The working population of the block was 26,081 , accounting to 2.90 percent of the district total population. The past two decades, (2001 to 2020) total literate persons of the Kolli Hills block were 8,772 and 21,073 respectively. The drop-out rate of Kollimalai taluk during 2013-14 was $1.50 \%$.

\section{Methodology}

The study was conducted in Kolli Hills Block of Namakkal district in Tamil Nadu in the year 2014-15. A sample of 144 tribal households was randomly selected from Valappurnadu village for collection of data and analysis. A complete enumeration of all the households in the village was done so as to identify their occupational pattern, educational status of parents, annual income of the family and other socio-economic characters suitable for the study. Both secondary and primary data were used. The cross sectional data required for the study were collected from the sample of select tribal households. A comprehensive pre-test schedule was prepared based on which information pertaining to the various aspects of the study were gathered through personal survey method.

A simple tabular and percentage analysis were 
made to study the socio-economic characteristics of the tribal households in the area. The impact of various factors influencing educational deprivation of women in Valappurnadu village was assessed through regression equation. The regression equation fitted for the cross sectional data was as follows:

$\mathrm{Y}=\mathrm{a}+\mathrm{b}_{1} \mathrm{X}_{1}+\mathrm{b}_{2} \mathrm{X}_{2}+\mathrm{b}_{3} \mathrm{X}_{3}+\mathrm{b}_{4} \mathrm{X}_{4}+\mathrm{b}_{5} \mathrm{X}_{5}+\mathrm{b}_{6} \mathrm{X}_{6}+\mathrm{b}_{7} \mathrm{X}_{7}$ Where,

$\mathrm{Y}=$ No. of drop-out of girls in a family

$\mathrm{X}_{1}=$ Education status of Father (in years)

$\mathrm{X}_{2}=$ Education status of Mother (in years)

$\mathrm{X}_{3}=$ Family size

$\mathrm{X}_{4}=$ Income of the family (in Rs.)

$\mathrm{X}_{5}=$ No. of working women in a family

$\mathrm{X}_{6}=$ Distance from home to school (in km)

$\mathrm{X}_{7}=$ Earner dependent ratio

$\mathrm{a}=$ Constant

$\mathrm{b}_{1 \ldots . . .} \mathrm{b}_{7}=$ regression co-efficient

\section{Limitation of the Study}

The present nature of the study involves mostly the primary data, collected from the sample respondents at a given point of time. Therefore, generalization derived from the study may or may not reflect to the future of this region. A survey method normally involves recall bias therefore; experimental accuracy cannot be expected in the data generated through this survey. Though the present study would be the first of this kind in Kolli Hill Block, the results of the study are confined only to the region and may not hold good to other tribal regions in the taluk.

\section{Results and Discussion}

The major findings of the present study are presented in two main parts viz., (i) socio-economic characteristics of the sample tribal households and (ii) Educational deprivation among women in Kolli Hills Block in Namakkal District.

\subsection{Part-I: Socio-Economic Characteristics of the Sample Tribal Households}

This part is mainly devoted for the study of the socioeconomic characteristics of the select sample tribal households in Valappurnadu village of Kolli Hills Block in Namakkal district. The important socio-economic characteristics chosen for analysis in the study are type of the family, family size, occupation of parents, annual income of the family, and educational status of Father and Mother among sample tribal households of different size group classified through post stratification method.

Table 1. Socio-economic characteristics of the sample tribal households

\begin{tabular}{|c|c|c|}
\hline Socio-economic characteristics & $\begin{array}{l}\text { Number } \\
(\mathrm{N}=144)\end{array}$ & Percentage \\
\hline \multicolumn{3}{|l|}{ Type of family } \\
\hline Joint & 63 & 43.75 \\
\hline Nuclear & 81 & 56.25 \\
\hline \multicolumn{3}{|l|}{ Family Size } \\
\hline$<3$ & 21 & 14.58 \\
\hline $3-6$ & 117 & 81.25 \\
\hline$>6$ & 6 & 4.17 \\
\hline \multicolumn{3}{|l|}{ Occupation of Parents } \\
\hline Agriculture & 33 & 22.92 \\
\hline Agricultural labour & 103 & 71.53 \\
\hline Others & 8 & 5.55 \\
\hline \multicolumn{3}{|l|}{ Annual income of the family } \\
\hline Below 20000 & 6 & 4.17 \\
\hline $20000-40000$ & 90 & 62.50 \\
\hline Above 40000 & 48 & 33.33 \\
\hline \multicolumn{3}{|l|}{ Education of father } \\
\hline Illiterate & 33 & 22.92 \\
\hline Primary level & 88 & 61.11 \\
\hline Secondary and above level & 23 & 15.97 \\
\hline \multicolumn{3}{|l|}{ Education of mother } \\
\hline Illiterate & 106 & 73.61 \\
\hline Primary level & 31 & 21.53 \\
\hline Secondary and above level & 7 & 4.86 \\
\hline
\end{tabular}

Source: Survey data

From Table 1, it is observed that out of the 144 sample tribal household selected for the study, the majority of them belonged to nuclear family; their family size had 3-6 members; their parents were primarily agricultural labourers and had a low family annual income of Rs.20,000 to Rs.40,000. The educational status of their parents was low as majority of the mothers were illiterate and fathers were educated upto primary level.

\subsection{Part-II: Educational Deprivation among Tribal Women}

This part examines the impact of some socio-economic variables viz., educational status of parents, family size, 
annual income, number of working women in a family, distance from home to school (access) and earnerdependent ratio that influences schooling of tribal female in Valappurnadu village.

Table 2. Estimated co-efficients of the regression equation among tribal women of Valappurnadu village in Kolli hills block

\begin{tabular}{|c|c|c|}
\hline Variables & Co-efficient & $\mathbf{t}$ \\
\hline Constant & -2.408 & -2.221 \\
\hline Educational Status of father & $-0.227^{\star}$ & -5.127 \\
\hline Educational Status of mother & 0.316 & 4.878 \\
\hline Family Size & $0.272^{\star \star}$ & 1.412 \\
\hline Log Annual Income & $0.001^{\star}$ & 2.844 \\
\hline No. of working women in the family & 0.232 & 0.427 \\
\hline Distance from home to school & $0.491^{\star}$ & 4.462 \\
\hline Earner - dependent ratio & 0.363 & 0.348 \\
\hline $\mathrm{R}^{2}$ & 0.796 & \\
\hline Adjusted R & 0.768 & \\
\hline F & 12.679 & 0.000 \\
\hline No. of Sample & 144 & \\
\hline
\end{tabular}

* Significant at $1 \%$ level ${ }^{* *}$ Significant at $5 \%$ level

The estimated regression co-efficients of the variables pertaining to the data on Valappurnadu village viz., (X1) Educational status of father, (X2) Educational status of mother, (X3) family size, (X4) monthly income, (X5) number of working women in a family, (X6) Distance from home to school and (X7) Earner - dependent ratio furnished in Table 2 clearly reveals that the coefficient of multiple determination $\left(\mathrm{R}^{2}\right)$ value of female school dropout as 0.796 . This indicates that much of the variation in the level of dropout from education among girls is explained by the regression model. All the co-efficients show expected signs. The co-efficient of educational status of father is negative and significant at $1 \%$ level. The size of the co-efficient indicates that if the educational status of household head (father) increases by one year, the probability of the girl's education being poor decreases by $23 \%$.

The co-efficient of the family size is positive and significant at $5 \%$ level. The magnitude of the co-efficient indicates that if the family size is large, then the probability of the girls' dropout from education increases by $27 \%$ and vice versa. The monthly income of the family is positive and statistically significant at $1 \%$ level. The magnitude of the co-efficient indicates that if the family income increases by $1 \%$, then the probability of the girls' dropout from education decreases by $0.1 \%$. The co-efficient of the distance from home to school is positive and significant at $1 \%$ level. The magnitude of the co-efficient indicates that if the distance from home to school decreases by one kilometer, then the probability of the girls' dropout from education decreases by $49 \%$. The education of mother, number of working women in the family and earner dependent ratio co-efficients are positive and statistically insignificant.

\section{Conclusion and Implications}

Thus, on the whole the study has emphasized the need for education of parents, particularly mother in reducing school dropout rate for girls. Female work participation plays a strong role in promoting secondary schooling in these areas. Low income of the family and the distance from home to school are the two factors found to be discouraging the parents from sending their girls to schools.

The following policy recommendations are suggested from the findings:

- Education ought to be imparted in mother tongue of the tribal people.

- $\quad$ Teachers having knowledge of tribal languages / dialects and socio-cultural values of tribal people should be selected. Preferably, the local educated people who are willing to stay and serve in the tribal areas should be appointed.

- $\quad$ Proper training should be given regarding tribal language, culture and society to the non-tribal teachers working in the tribal areas.

- Massive and special efforts ought to be made for the enrolment of ST girls.

- In mixed areas, establishing separate schools and hostels might encourage segregation.

\section{References}

1. Cladwell, J.C., Reddy P.H., and Pat C. "Education Transition in Rural South India". Population and Development Review, vol. 11 No. 1, 1985, pp.29-51.

2. Sujatha.K, "Education of Indian Scheduled Tribes: A Study of Community Schools in the district of Vishakhaparnam, Andhra Pradesh". International Institute for Educational Planning, 1999, p. 184.

3. Unni J. "Who is Schooled and Why", Gender Perspective in Population, Health and Development Conference, New Delhi: National Council of Applied Economics Research, 1996. 
4. Dreze J., and Gazdar H. "Uttar Pradesh: Burden of Inertia", In Dreze, J. and Sen, A.(Ed), Indian Development:Selected Regional Perspectives. New Delhi: Oxford University Press, 1997, pp. 33-128.

5. Nambisan G. "Schooling of Children in Rural Rajesthan: A Study of Jhadol and Alwar Tehsils", Zakir Husain Centre for Development Studies, Jawaharal Nehru University for UNDP-GOI Research Programme in Human Development, 1994.

6. Majumdar M. "Kanyakumari: The Loading Edge of Education in Tamil Nadu", Madras: Madreas Institute of Development Studies for UNDP-GOI Research Programme of Human Development, 1996.
7. Srivastava R.S. "Access to Basic Education in Utter Pradesh", University of Allahabad, UNDP-GOI Research Programme of Human Development, 1997.

8. Shivalli R., Rao S., and Chitagubbi G., "Resourcefulness of the School Going and Non-school Going Girls to the Family in Rural Areas". Studies on Home and Community Science, Vol. 4(2), pp. 129-132, 2010.

9. Khan S., and Pandey G. "Dropout is a Black Spot on Education System (a study on female dropouts in Aligarh district)" In Imran Saleem and Ashraf Imam (Ed), Education in Emerging Indian Society, APH Publishing Corporation, 2012, pp. 87-91. 